\title{
Response of Environment and Stability on Grain Yield in Promising Genotypes of Rice (Oryza sativa L.)
}

\author{
N.R. Koli*, P.K.P. Meena, Manoj Kumar and Sandhya \\ Agricultural Research Station, Ummedganj Farm, \\ Kota-324001 (Agricultural University, Kota), India \\ *Corresponding author
}

\begin{tabular}{l} 
Ke y w o r d s \\
Yield, Stability \\
parameters, G x E \\
interaction, \\
$\begin{array}{l}\text { Environmental } \\
\text { response and } \\
\text { Oryza sativa L }\end{array}$ \\
\hline Article Info \\
$\begin{array}{l}\text { Accepted: } \\
\text { 17 June } 2019 \\
\text { Available Online: } \\
\text { 10 July } 2019\end{array}$ \\
\hline
\end{tabular}

\section{A B S T R A C T}

The present investigation was determining the response of environment and stable genotypes across the environments. Ten promising genotypes of rice were evaluated for their adaptability in respect of grain yield for three years 2014-2016. The stability parameters were estimated by using the method of Eberhart and Russell 1966. Table 1 showed highly significant yield differences among the genotypes, environment and GxE interaction. The general mean $(\mathrm{X})$, regression coefficient (bi) and deviation from regression $\left(\mathrm{S}^{2} \mathrm{di}\right)$ were considered as stability parameters. Variety P 2511, P 1121, Pratap 1 and promising genotype IET 21960 were found stable or better responsive in general adaptation but the genotype IET 21593 showed below average stability and found suitable for favorable environment, whereas the genotype IET 21959, IET 22290 \& P-1460 were found unstable. Therefore these genotypes which are general in adaptation may be commercially cultivated over a wide range of environments.

\section{Introduction}

The yield stability performance is one of the most desirable properties of genotypes to be released as a variety for commercial cultivation. The genotypes that are adapted throughout a reasonable large geographical area and that show some degree of stability from year to year is a major problem facing plant breeders. As a result, several methods of measuring and describing genotypic response across environments have been developed and utilized. For this purpose multilocation trials, over a number of year are conducted. Sometimes unilocation trials can also serve the purpose provided different environment (Mosavi et al., 2013). Varietal adaptability to environmental fluctuations is very important for stabilization of crop production over both regions and years. An information on genotype $\mathrm{x}$ environment interaction leads to successful evaluation of stable genotype which could be used general cultivation (Koli et al., 2018). Yield is a complex trait and is 
greatly influenced by environmental fluctuation; hence the selection for superior genotype based on yield per se at a single location in a year may not be very effective. Thus, varietal stability of paramount importance for stabilizing the production over regions and seasons as land holding in general of small size and farmers are resource poor (Koli and Prakash, 2012).

Stability has been used by various researchers (Eberhart and Russell, 1966; Finley and Wilkinson, 1967) to decide whether the performance of a genotype was satisfactory. Stability and adaptability studies very useful for releasing a genotype for cultivation under wide as well as specific environments. However, this information is lacking in rice, hence the present investigation was undertaken to determine the environmental response and stability analysis, adaptability and sustainability index of five release varieties and some promising genotypes of rice.

\section{Materials and Methods}

The material for present investigation was consisted of five released variety of rice $(\mathrm{P}$ 1121, P-2511, P 1460, Taraori basmati and Pratap-1 along with five promising genotypes viz., IET 21953, IET 21959, IET 21960, IET 22289 and IET 22290. These genotypes were laid out in randomized block design with three replications with row to row spacing of $20 \mathrm{~cm}$ and plant to plant distance of $10 \mathrm{~cm}$ in each environment during three years (2014 to 2016) at Agricultural Research Station, Ummedganj, Kota, to determine the environment response and stability. All the cultural practices were adopted during the entire cropping season to ensure a good crop. The data for grain yield was recorded on plot basis and estimated in $q /$ ha. The three years data on each variety were used for estimation of stability parameters by using the Eberhart and Russell (1966) model and sustainability index was estimated according to following formula used by other workers (Singh and Agarawal, 2003; Gangwar et al., 2004; Tuteja, 2006).

Sustainability index $($ S.I. $)=(\mathrm{Y}-$ Ón $) / \mathrm{Y}_{\mathrm{M}} \mathrm{X}$ 100

Where, $\mathrm{Y}=$ Average performance of a genotype,

Ón = standard deviation and

$\mathrm{Y}_{\mathrm{M}}=$ Best performance of a genotype in any year.

The value of sustainability index were arbitrarily divided in to five group viz. very low (up to 60\%), low (61- $70 \%$ ), moderate (71-80\%), high (81-90) and very high (above $90 \%)$

The yield differences were found to be significant over years, indicating genetic difference among the varieties. For drawing meaningful interference, the yield (best performance) and sustainability index could be divided into four groups as follows;

\section{Results and Discussion}

Pooled analysis of variance (Table 1) showed highly significant differences for genotypes, environment and $G \times \quad E$ interactions. Significant mean squares due to genotype $\mathrm{x}$ environment interactions indicated differential response of genotypes in different environments. It means a particular variety may not exhibit the same phenotypic performance under different environments or different varieties may respond differently to a specific environment. Significant genotypic interaction was earlier reported by Panwar et al., (2008) Ummadevi et al., (2011) and Koli et al., (2016) and (2018) in rice. Both linear and non-linear components of $G \quad x \quad E$ interactions were also found significant for grain yield showing the importance of both 
linear (predictable) and non-linear (unpredictable) components in the expression of the traits. The linear component was significant as against the nonlinear components (Pooled deviation), which revealed that a large portion of $\mathrm{G} \times \mathrm{E}$ interaction was accounted for by linear regression although pooled deviation was significant. These results were in confirmation to those reported by Koli et al., (2018), Panwar et al., (2008) and Umadevi et al., (2011) in rice.

The mean performance, regression coefficient (bi) and mean square deviation from regression $\left(\mathrm{S}^{2} \mathrm{~d}\right)$ were presented in Table 2 . Data revealed that variety P-1121, P-2511, Pratap-1 and promising genotype IET 21960 have high mean values, regression coefficient close to unity (bi =1) and least square deviation $\left(S^{2} d=0\right)$ for grain yield, indicated that these varieties were better responsive to all the environments and were considered as stable genotypes. The promising genotype IET 21953 and IET 22289 produced above average yield with non-significant unit regression value and deviation from regression (0), indicated below average stability, such genotypes tend to respond favorably to better environments but give poor yield in unfavorable environments. Hence, these genotypes were suitable for favorable environments. Whereas the variety P 1460 and promising genotypes IET 22959 and IET 22290 indicated low mean with significant bi and $\mathrm{S}^{2} \mathrm{~d}$ values, are unstable.

Eberhart and Russell (1966) also defined a stable genotype as the one which showed high mean yield, regression coefficient (bi) around unity and deviation from regression near to zero. Accordingly, the mean and deviation from regression of each variety were considered for stability and linear regression was used for testing the varietal response.

Genotypes with high mean, bi $=1$ with nonsignificant $\mathrm{s}^{2} \mathrm{~d}$ are suitable for general adaption, i.e. suitable over all environmental conditions and they are considered as stable genotype.

Genotypes with high mean, bi $>1$ with nonsignificant $\mathrm{s}^{2} \mathrm{~d}$ are considered as below average in stability. Such genotypes tend to respond favorably to better environments but give poor yield in unfavorable environments. Hence, they are suitable for favorable environments.

\begin{tabular}{|c|c|c|}
\hline Yield (Best Performance) & Sustainability index & Remarks \\
\hline High & High & Desirable \\
\hline High & Low & Location specific \\
\hline Low & High & Undesirable \\
\hline Low & Low & Undesirable \\
\hline
\end{tabular}

Table.1 Pooled analysis of variance for grain yield (q/ha) of promising rice genotypes

\begin{tabular}{|l|c|c|}
\hline Sources & Degree of freedom & Mean squares \\
\hline Genotype & 9 & $123.3744^{* *}$ \\
\hline Environ & 2 & $41.3182^{* *}$ \\
\hline G X E & 18 & $4.1687^{* *}$ \\
\hline E+(GXE) & 20 & $2.6279^{*}$ \\
\hline E linear & 1 & $1.3772^{* *}$ \\
\hline G X E linear & 9 & $4.5309^{* *}$ \\
\hline Pooled Deviation & 10 & $1.0402^{* *}$ \\
\hline Pooled Error & 60 & $0.06109^{* *}$ \\
\hline
\end{tabular}

*, ** Significant against pooled deviation mean squares at $5 \%$ and $1 \%$, respectively 
Table.2 Stability parameters for grain yield (q/ha) of promising rice genotypes

\begin{tabular}{|c|c|c|c|}
\hline Varieties/ Genotypes & $\begin{array}{c}\text { Mean grain } \\
\text { yield (q/ha) }\end{array}$ & Regression coefficient (bi) & $\begin{array}{c}\text { Deviation from regression } \\
\text { (s. }\end{array}$ \\
\hline IET 21953 & 46.15 & 0.652 & -0.8 \\
\hline IET 21959 & 45.41 & $3.918^{* *}$ & $4.1^{* *}$ \\
\hline IET 21960 & 46.37 & 1.00 & 0.5 \\
\hline IET 2289 & 45.92 & 0.753 & 0.2 \\
\hline IET 22290 & 44.79 & $4.988^{* *}$ & $1.6^{*}$ \\
\hline P 1121 & 47.24 & 1.076 & 0.0 \\
\hline P 1460 & 44.77 & $2.898^{*}$ & $1.6^{*}$ \\
\hline Taraori Basmati & 36.00 & $2.732^{*}$ & 0.6 \\
\hline P-2511 & 48.27 & 1.018 & 0.3 \\
\hline Pratap-1 & 49.97 & 0.964 & 0.4 \\
\hline Mean & 45.48 & & \\
\hline
\end{tabular}

*, ** Significant at $5 \%$ level of probability.

Table.3 Estimates of sustainability index for grain yield in promising rice genotypes

\begin{tabular}{|c|c|c|c|c|}
\hline Varieties & $\begin{array}{c}\text { Mean grain } \\
\text { yield (q/ha) } \mathbf{Y}\end{array}$ & $\begin{array}{c}\text { Standard } \\
\text { deviation Ón }\end{array}$ & $\begin{array}{c}\text { Best performance of a } \\
\text { genotype in any year }\left(\mathbf{Y}_{\mathbf{M})}\right.\end{array}$ & $\begin{array}{c}\text { Sustainability } \\
\text { index (\%) }\end{array}$ \\
\hline IET 21953 & 46.15 & 1.436 & 49.55 & 90.24 \\
\hline IET 21959 & 45.41 & 2.941 & 50.53 & 84.06 \\
\hline IET 21960 & 46.37 & 1.603 & 48.88 & 91.59 \\
\hline IET 22289 & 45.92 & 3.624 & 48.00 & 88.11 \\
\hline IET 22290 & 44.79 & 3.729 & 48.54 & 84.59 \\
\hline P 1121 & 47.24 & 1.422 & 49.11 & 83.29 \\
\hline P 1460 & 44.77 & 3.269 & 49.87 & 78.11 \\
\hline Taraori Basmati & 36.00 & 3.801 & 41.22 & 91.45 \\
\hline P-2511 & 48.27 & 1.627 & 51.00 & 95.36 \\
\hline Pratap-1 & 49.97 & 1.149 & 51.20 & \\
\hline Mean & 45.48 & & & \\
\hline
\end{tabular}

Table.4 Comparison between the Eberhart and Russell model and Sustainability Index

\begin{tabular}{|c|c|c|c|c|c|c|}
\hline \multirow{2}{*}{$\begin{array}{c}\text { Varieties/ } \\
\text { Genotypes }\end{array}$} & $\begin{array}{c}\text { Mean grain } \\
\text { yield (q/ha) }\end{array}$ & \multicolumn{2}{|c|}{ Eberhart and Russell model } & \multicolumn{2}{c|}{ Sustainability index (\%) } \\
\cline { 5 - 7 } & $(\mathbf{b i})$ & $\left(\mathbf{s}^{\mathbf{2}} \mathbf{d}\right)$ & Rating & SI $(\%)$ & Rating \\
\hline IET 21953 & 46.15 & 0.652 & -0.8 & Stable & 90.24 & high \\
\hline IET 21959 & 45.41 & $3.918^{* *}$ & $4.1^{* *}$ & Un Stable & 84.06 & high \\
\hline IET 21960 & 46.37 & 1.00 & 0.5 & Stable & 91.59 & Very high \\
\hline IET 22289 & 45.92 & 0.753 & 0.2 & Stable & 88.11 & high \\
\hline IET 22290 & 44.79 & $4.988^{* *}$ & $1.6^{*}$ & Un Stable & 84.59 & high \\
\hline P 1121 & 47.24 & 1.076 & 0.0 & Stable & 93.29 & Very high \\
\hline P 1460 & 44.77 & $2.898^{*}$ & $1.6^{*}$ & Un Stable & 83.22 & high \\
\hline Taraori Basmati & 36.00 & $2.732^{*}$ & 0.6 & Un Stable & 78.11 & Moderate \\
\hline P-2511 & 48.27 & 1.018 & 0.3 & Stable & 91.45 & Very high \\
\hline Pratap-1 & 49.97 & 0.964 & 0.4 & Stable & 95.36 & Very high \\
\hline Mean & 45.48 & & & & & \\
\hline
\end{tabular}

${ }^{1}=$ below Average yield . 
Genotypes with low mean, bi<1 with nonsignificant $\mathrm{s}^{2} \mathrm{~d}$ do not respond favorably to improved environmental conditions and hence, it could be regarded as specifically adapted to poor environments.

Genotypes with any bi value with significant $\mathrm{s}^{2} \mathrm{~d}$ are unstable.

Sustainability index was also used to identify the stable genotypes. The average grain yield $\left(\mathrm{Y}_{\mathrm{M}}\right.$ ), standard deviation (Ón) and sustainability index (SI \%) of each genotype has been given in Table 3. Very high sustainability index (\%) was observed in Pratap-1(95.33) followed by P 1121 (93.29), IET 21960 (91.45) and P 2511 (91.4). Whereas, moderate to high sustainability was observed in rest of all.

The comparison of Eberhart and Russell (1966) model with new model based on sustainability index (Table 4) revealed that IET 22289 contradict with respect to the stability parameters and the sustainability index. According to Eberhart and Russell model of stability analysis IET 21959, IET 22290, P-1460 and Taraori basmati were found as unstable but it having moderate to high sustainability index.

In the present study, Eberhart and Russell model was found to be more robust for predicting the stable genotype. The stable genotype with respect to the seed yield under variable environments may be useful in breeding programme for evolving high yielding genotypes adapted in this zone. Rice varieties P 1121, P 2511 and Pratap-1 and promising genotype IET 21953 and IET 21960 have sown stable performance under different environment by having above average seed yield, non-significant unit regression coefficient along with the nonsignificant variance due to deviation from regression. On the basis of these results, says that, these varieties/ genotypes are suitable for commercial cultivation over a wide range of environment.

\section{Acknowledgement}

Authors are grateful thanks to Director Research, Agriculture University, Kota, Zonal Director Research, ARS, Kota, and also grateful thanks to Project Director, IIRR, Hyderabad, for providing necessary facilities and financial support to conduct the research work.

\section{References}

Eberhart, S. and W.A. Russell. 1966. Stability parameters for comprising varieties. Crop Sci., 6: 36-40.

Finley, R.W. and G.N. Wilkinson. 1963. The analysis of adaption in plant breeding programme. Aust. J. Agric. Res., 14: 742-754.

Gangwar, B., V. Katyal and K.V. Anand. 2004. Stability and efficiency of cropping system in Chhattisgarh and Madhya Pradesh. Indian J. Agril. Sci., 74: 521-528.

Koli N. R. and Prakash C. 2012. Genotype x Environment interactions and adaptability with sustainability index and their comparison in aromatic rice (Oryza sativa L.) under transplanted rice. Int. J. Agri. Env. Biotech. 5 (4) 365-368.

Koli N. R; Kumar M; Sandhya; Meena R. K; and Patidar B.K. 2018. G $\quad$ X $\quad$ E interaction, sustainability index and their comparison in rice. International Journal of Chemical Studies. 7(3): 940941.

Koli N. R; Kumhar B. L; Mahawar R. K; Bagri R.K. and Prakash C. 2016. Selection of stable genotype on the basis of stability performance and sustainability index in rice (Oryza 
sativa L.). Electronic Journal of Plant Breeding. 7(4): 967-971.

Mosavi A. A; Jalodar N.B. and Kazemitabar K. 2013. Environmental response and stability for grain yield of some rice genotypes. World Applied Sci. J. 21 (1): 105-108.

Panwar, L.L., V.N. Joshi and A. Mashiat. 2008. Genotypic x Environment interaction in scented rice. Oryza, 45(1): 103-109.

Singh, P. and K. Agrawal. 2003. Sustainability index as an aid determining genotypic stability in diploid cotton (Gossypium arboretum). J. Cotton Res. Dev., 17 (1): 90-92.

Tuteja, O. P. 2006. Comparative studies on stability parameters and sustainability index for selecting stable genotypes in diploid cotton (Gossypium hirsutum L.). Indian J. Genet., 66(3): 221-224

Umadevi, M., P. Veerabadhiran and S. Manonmani. 2011. Stability analysis for grain yield and its components traits in rice (Oryza sativa L.). J. of Rice Res., 3(1) $10-12$.

\section{How to cite this article:}

Koli, N.R., P.K.P. Meena, Manoj Kumar and Sandhya. 2019. Response of Environment and Stability on Grain Yield in Promising Genotypes of Rice (Oryza sativa L.). Int.J.Curr.Microbiol.App.Sci. 8(07): 2170-2175. doi: https://doi.org/10.20546/ijcmas.2019.807.262 